\title{
Flagellin/NLRC4 Pathway Rescues NLRP3-Inflammasome Defect in Dendritic Cells From HIV-Infected Patients: Perspective for New Adjuvant in Immunocompromised Individuals
}

Edione Cristina dos Reis ${ }^{1 *}$, Vinícius Nunes Cordeiro Leal ${ }^{1}$, Jaíne Lima da Silva Soares ${ }^{1}$, Fernanda Pereira Fernandes ${ }^{1}$, Dhêmerson Souza de Lima ${ }^{1}$, Bruna Cunha de Alencar ${ }^{2}$ and Alessandra Pontillo ${ }^{1}$

${ }^{1}$ Laboratory of Immunogenetics, Department of Immunology, Institute of Biomedical Sciences/ICB, University of São Paulo/USP, São Paulo, Brazil, ${ }^{2}$ Laboratory of Immune System Cell Biology, Department of Immunology, Institute of Biomedical Sciences/ICB, University of São Paulo/USP, São Paulo, Brazil

\section{OPEN ACCESS}

Edited by:

Daniela Santoro Rosa

Federal University of São Paulo, Brazil

Reviewed by:

Osamu Takeuchi,

Kyoto University, Japan

Ezequiel Ruiz-Mateos,

Institute of Biomedicine of Seville

(IBIS), Spain

*Correspondence: Edione Cristina dos Reis

edionereis@usp.br

Specialty section: This article was submitted to Antigen Presenting Cell Biology,

a section of the journal

Frontiers in Immunology

Received: 30 July 2018 Accepted: 21 May 2019

Published: 11 June 2019

Citation:

Reis EC, Leal VNC, Soares JLS, Fernandes FP, Souza de Lima D, de Alencar BC and Pontillo A (2019)

Flagellin/NLRC4 Pathway Rescues NLRP3-Inflammasome Defect in Dendritic Cells From HIV-Infected

Patients: Perspective for New Adjuvant in Immunocompromised Individuals. Front. Immunol. 10:1291.

doi: 10.3389/fimmu.2019.01291
Introduction: NLRP3 inflammasome plays a key role in dendritic cells (DC) activation in response to vaccine adjuvants, however we previously showed that it is not properly activated in DC from HIV-infected patients (HIV-DC), explaining, at least in part, the poor response to immunization of these patients. Taking in account that several cytoplasmic receptors are able to activate inflammasome, and that bacterial components are considered as a novel and efficient adjuvant, we postulated that bacterial flagellin (FLG), a natural ligand of NAIP/NLRC4 inflammasome, could rescue the activation of the complex in HIV-DC.

Objective: Demonstrate that FLG is able to activate monocyte-derived dendritic cells from HIV-infected individuals better than LPS, and to what extent the entity of inflammasome activation differs between DC from HIV-infected patients and healthy donors.

Methods: Monocyte-derived dendritic cells from HIV-infected patients (HIV-DC) and healthy donors (HD-DC) were stimulated with FLG, and inflammasome as well as DC activation (phenotypic profile, cytokine production, autologous lymphocytes activation) were compared. Chemical and genetic inhibitors were used to depict the relative contribution of NLRC4 and NLRP3 in HIV/HD-DC response to FLG.

Results: FLG properly activates HD-DC and HIV-DC. FLG induces higher inflammasome activation than LPS in HIV-DC. FLG acts through NLRC4 and NLRP3 in HD-DC, but at a lesser extent in HIV-DC due to intrinsic NLRP3 defect.

Conclusions: FLG by-passes NLRP3 defect in HIV-DC, through the activation of NAIP/NLRC4 inflammasome, indicating possible future use of the bacterial component as an efficient adjuvant in immunocompromised individuals.

Keywords: dendritic cell, inflammasome, HIV, flagellin, NLRC4, adjuvant 


\section{INTRODUCTION}

Dendritic cells (DC) are a specialized professional antigen presenting cells (APC) with unique capability to initiate and maintain primary immune responses when pulsed with antigens (1-3). Following recognition of pathogen- or damage-associated molecular patterns (PAMPs or DAMPs, respectively) by innate pattern recognition receptors (PRRs), DC activate and turn into a potent APC. The final differentiation of activated DC is characterized by plasma membrane up-regulation of MHCII and co-stimulatory molecules (i.e., CD86, CD80), and the production of cytokines important for $\mathrm{T} \mathrm{CD}_{4}^{+}$lymphocytes activation at the immunologic synapsis (i.e., IL-12 and IL18; and/or IL-1ß; or IL-4). The result of DC activation drives the polarization of $\mathrm{T} \mathrm{CD} 4^{+}$lymphocytes, and therefore of the immune response (4).

Successful vaccine preparations have to properly activate DC to induce a long-term memory protective immunity. Together with pathogen' antigens, adjuvants strongly contribute to the effectiveness of a vaccine. Their action is mediated by DC PRRs, such as Toll-like receptors (TLRs) and NACHT and LRR containing receptors (NLRs), through the activation of intracellular pathways leading to the production of cytokines important for $\mathrm{T}$ cell activation (5). Alum (aluminum hydroxide), a commonly used adjuvant, activates murine DC through the induction of the NLRcontaining a PYD domain 3 (NLRP3) and the consequent mounting of the cytoplasmic complex, known as inflammasome, which results in caspase-1 activation and IL- $1 \beta$ and IL-18 production. The absence of NLRP3 results in the loss of adjuvant responsivity (6), emphasizing the central role of inflammasome in the activation of DC and in the induction of an efficient immune response.

Accordingly, recent findings have reported that individuals with a low response to vaccines, such infants (7) or cancer patients (8) present a substantial alteration in inflammasome expression and/or activity.

Immune response to many current vaccines is known to be impaired and/or less effective in chronically HIV-infected individuals (9). This impairment has been associated to both a reduced frequency of DC $(10,11)$, together with phenotypic and functional alterations of these cells (12). As HIV-infected patients present well-documented DC impairment, it has been proposed that a poor response to vaccination could be caused by a diminished and/or defective response to common adjuvants (13).

We have previously demonstrated that NLRP3 inflammasome is not correctly activated by bacterial lipopolysaccharide (LPS) in monocyte-derived dendritic cells (MDDC) from HIV-infected patients (HIV-DC) (14), possibly as a result of the HIVassociated chronic inflammation and the consequent immune system exhaustion (15). As NLRP3 inflammasome is involved in the activation of DC by vaccine adjuvants $(6,16)$, the defect observed in NLRP3 inflammasome possibly contributes to the less extend immunization response in HIV-infected individuals.

To counteract the low immune response, new vaccination strategies have been proposed, such as the use of PRRs agonists, such as LPS or flagellin (FLG), as largely reviewed in (17).
FLG is the main component of a bacterial flagellum, and it is recognized extracellularly by TLR5 inducing a Myd88 signaling and promoting the transcription of NF- $\mathrm{KB}$-related genes $(18,19)$; and by the intracellular receptors, NLR-containing a BIR domain (NAIP) and NLR-containing a CARD domain (NLRC)-4. NAIP directly binds FLG, while NLRC4 recognizes the NAIP:FLG complex and mounts the NAIP/NLRC4 inflammasome, resulting in IL- $1 ß$ and IL-18 production (20-22).

FLG has already been used as an adjuvant in a number of clinical trials of healthy individuals $(23,24)$, however to our knowledge none or poor data are available about its ability to activate MDDC in both healthy or immuno-compromised individuals via NAIP/NLRC4 inflammasome.

Taking in account the key role of the inflammasome in proper DC activation, and the impairment of NLRP3 activation observed in HIV-DC, we hypothesize that FLG could represent an alternative adjuvant for HIV-infected patients, by activating inflammasome in DC through NAIP and NLRC4 receptors, and in this way by-passing the NLRP3 defect. Therefore, the aim of this study was to demonstrate that FLG is able to activate MDDC from HIV-infected individuals better than LPS, and to what extent the entity of inflammasome activation differs between HIV-DC and HD-DC.

\section{MATERIALS AND METHODS}

\section{HIV-Infected Patients}

Twenty-seven HIV-infected adults patients ( 16 males/11 females; $51.9 \pm 11.7$ years), proceeding from the metropolitan area of São Paulo (SP, Brazil), seropositive for at least 5 years (26.9 \pm 16.9 years), in antiretroviral therapy (ART), with blood $\mathrm{CD}^{+} \mathrm{T}$ cells count $>500$ cells $/ \mu \mathrm{l}$, without clinical AIDS or other chronic diseases (i.e., neoplasias, cardiovascular disease, autoimmune disease, kidney disease, obesity) or infectious diseases (i.e., human T-lymphotropic virus/HTLV, hepatitis B or hepatitis C virus), were recruited from January 2016 to May 2018 at the "Serviço de Extensão ao Atendimento de Pacientes HIV/AIDS" (SEAP) of the Faculty of Medicine, University of São Paulo (São Paulo, SP, Brazil). Fifty milliliter of the peripheral blood was collected in heparin tubes. All volunteers assigned the informed consent approved by the Institutional Ethical Committee. Patients' main characteristics are summarized in Table 1.

\section{Healthy Donors (HD)}

Twenty-seven adults (15 males/12 females; $45.5 \pm 13.4$ years), proceeding from the metropolitan area of São Paulo (SP, Brazil), without clinical HIV or other chronic or infectious diseases, were recruited at the Blood Bank Service of the Hospital "Oswaldo Cruz" (São Paulo, SP, Brazil). Fifty milliliter of the peripheral blood was collected in heparin tubes. All volunteers assigned the informed consent approved by the Hospital Ethical Committee. HD demographic data were included in Table 1. Of note, any significant difference exists in gender ratio (Fisher test $p>$ $0.05)$ or age mean value ( $t$ - test $p>0.05)$ between HD and HIV-infected patients. 
TABLE 1 | Main characteristics of healthy donors and HIV-infected patients.

\begin{tabular}{|c|c|c|}
\hline & HD $(n=27)$ & HIV $(n=27)$ \\
\hline Gender (M/F), n & $15 / 12$ & $16 / 11$ \\
\hline Age (years), mean \pm SD & $45.5 \pm 13.4$ & $51.9 \pm 11.7$ \\
\hline Time from diagnosis (years), mean \pm SD & & $26.9 \pm 16.9$ \\
\hline PVL* (log RNA copies $/ \mu L)$, mean \pm SD & & $1.77 \pm 0.37$ \\
\hline $\mathrm{PVL}^{0}(\log \mathrm{RNA}$ copies $/ \mu \mathrm{L})$, mean $\pm \mathrm{SD}$ & & $4.00 \pm 1.02$ \\
\hline $\mathrm{PVL}^{1}$ (log RNA copies $\left./ \mu \mathrm{L}\right)$, mean $\pm \mathrm{SD}$ & & $2.25 \pm 0.77$ \\
\hline $\mathrm{CD}^{+}{ }^{+} \mathrm{T}^{*}$ (cells $\left./ \mu \mathrm{L}\right)$, mean $\pm \mathrm{SD}$ & & $768.9 \pm 283.1$ \\
\hline $\mathrm{CD}^{+}+\mathrm{T}^{0}(\mathrm{cell} / \mathrm{s} / \mu \mathrm{L})$, mean $\pm \mathrm{SD}$ & & $377.5 \pm 389.9$ \\
\hline $\mathrm{CD}^{+}{ }^{+} \mathrm{T}^{1}(\mathrm{cell} s / \mu \mathrm{L})$, mean $\pm \mathrm{SD}$ & & $679.0 \pm 252.7$ \\
\hline
\end{tabular}

Gender and age are reported for healthy donors (HD) and HIV-infected patients (HIV). Time from HIV-1 diagnosis as well as plasma viral load (PVL) and $C D 4^{+} T$ cells counts at the time of blood collection ( $\left.{ }^{(}\right)$, before $(\rho)$ and after ( $\left.{ }^{(}\right)$the start of anti-retroviral therapy (ART) were included for HIV-infected patients. The detection limit of PVL was $1.70 \mathrm{log} H I V-1$ $R N A$ copies $/ \mathrm{ml}$. M, males; $F$, females; $n$, number of individuals; SD, standard deviation.

\section{Human Monocyte-Derived Dendritic Cells (MDDC)}

Mononuclear cells were isolated from $50 \mathrm{~mL}$ of peripheral blood by Ficoll-Hypaque (GE Healthcare) density gradient, and monocytes were separated from lymphocytes by plastic adherence. Briefly, $4 \times 10^{6}$ mononuclear cells/well were incubated in 24-wells culture plates (Corning-Costar). After $2 \mathrm{~h}$, non-adherent cells (mainly lymphocytes) were removed and cryopreserved at $-80^{\circ} \mathrm{C}$ for co-culture assays, while adherent cells (mainly monocytes) were cultured with $50 \mathrm{ng} / \mathrm{mL}$ GMCSF (Peprotech) and $50 \mathrm{ng} / \mathrm{mL}$ IL-4 (Peprotech) in RPMI-1640 (Gibco, Thermo Fisher Scientific) supplemented with $10 \%$ of fetal bovine serum (FBS; Gibco) at $37^{\circ} \mathrm{C}$ in $5 \% \mathrm{CO}_{2}$ for 5 days (25). Monocytes-to-DC differentiation was confirmed by flow cytometry analysis of CD14 and CD11c surface markers (Supplementary File 1).

MDDC (HIV-DC or HD-DC) were stimulated with purified $5 \mu \mathrm{g} / \mathrm{mL}$ FLG from S. typhimurium (FLA-ST, Invivogen) or $1 \mu \mathrm{g} / \mathrm{mL}$ LPS from E. coli (Sigma-Aldrich, Merck) for 3, 8, 18, and $24 \mathrm{~h}$ and $1 \mathrm{mM}$ ATP was added for more $15 \mathrm{~min}$ (26). In some experiments, MDDC were pre-incubated with $10 \mu \mathrm{g} / \mathrm{mL}$ MCC-950 (Invivogen), a specific NLRP3 inhibitor (27), or $10 \mu \mathrm{M}$ parthenolide (PTD; Sigma-Aldrich, Merck), a NF-kB and caspases inhibitor (28); or with 1,000 UI/mL IFN- $\alpha-2 b$ (ScheringPlough) for $18 \mathrm{~h}(29,30)$. Cell supernatants were collected for cytokines measurement. MDDC were used for cytometric assays or RNA isolation and genes expression analysis.

To assess MDDC ability to activate $\mathrm{CD}^{+}{ }^{+} \mathrm{T}$ lymphocytes, $0.4 \times 10^{5}$ MDDC were distributed in 96-well U-bottom suspension culture plates with $4.0 \times 10^{5}$ autologous lymphocytes (cryopreserved non-adherent peripheral blood mononuclear cells) (co-culture MDDC/lymphocytes ratio: 1/10) in duplicates and cultured in the presence of unspecific (not antigen-specific) stimuli for 96 or $120 \mathrm{~h}$ to measure IFN- $\gamma$ production and lymphocytes proliferation, respectively. Lymphocytes alone were used as a negative control ( $\mathrm{Neg})$.

\section{MDDC Phenotype Analysis}

$2 \times 10^{5} \mathrm{DC} / \mathrm{mL}$ were incubated in Phosphate Buffer Saline (PBS; Sigma-Aldrich, Merck) with the optimal dilution of anti-CD14 PE (MEM15; Exbio), anti-CD11c (3.9; Biolegend), anti-HLA-DR V500 (G46-6; BD Biosciences), anti-CD86 PE-cy7 (2331/FUN$1, \mathrm{~B}$ ), and anti-CD40 Horizon 450 (5C3; BD Biosciences) antibodies for $20 \mathrm{~min}$ at $4^{\circ} \mathrm{C}$. Cells were then washed twice with PBS and resuspended in $200 \mu \mathrm{L}$ of $4 \%$ FormaldehydePBS. The Live/Dead Fixable Cell Stain Kit (Life Technology, Thermo Fisher Scientific) was added to the assay according to the manufacturer's instructions. A minimum of 50,000 events was acquired on a LSRFortessa ${ }^{\mathrm{TM}} \mathrm{X}-20$ flow cytometer (BD Biosciences) using the FACS Diva software (BD Biosciences). Data were analyzed using the FlowJo software (Tree Star). The gates strategy for one representative experiment was reported in Supplementary File 2.

\section{CD4 $^{+}$T Lymphocytes Activation Assay}

$\mathrm{CD} 4^{+} \mathrm{T}$ lymphocytes activation was measured by the meaning of intracellular staining of IFN- $\gamma$. Briefly, autologous co-cultures of MDDC and lymphocytes were treated with lymphocyte mitogens Ionomycin $(1 \mu \mathrm{g} / \mathrm{mL}$; Sigma-Aldrich, Merck) and Phorbol Myristate Acetate (10 ng/mL; Sigma-Aldrich, Merck) for $96 \mathrm{~h}$ (31). Twenty microgram per milliliter Brefeldin A (SigmaAldrich, Merck) was added $6 \mathrm{~h}$ before the end of co-culture to block Golgi secretory pathway. Cells were then labeled for surface marker anti-CD3 APC (MEM-57) and anti-CD4 PE (RPAT4) (BD Biosciences), permeabilized with Cytofix/Cytoperm solution (BD Biosciences), and finally stained for anti-IFN- $\gamma$ V450 (B27; BD Biosciences). The Live/Dead Fixable Cell Stain Kit was added to the assay according to the manufacturer's instructions. Cells were then washed twice with PBS and resuspended in $200 \mu \mathrm{L}$ of $4 \%$ Formaldehyde-PBS to proceed to flow cytometry analysis as above-mentioned.

\section{CD4 $^{+}$T Lymphocytes Proliferation Assay}

The CFSE Cell Division Tracker Kit (Biolegend) was used for flow cytometry analysis of in vitro $\mathrm{CD} 4^{+} \mathrm{T}$ cells proliferation assay according to manufacturers' protocol. Briefly, autologous lymphocytes were pre-treated with $0.1 \mu \mathrm{M}$ CFSE before being added to MDDC cultures in the presence of the lymphocyte mitogen Concanavalin A $(5 \mu \mathrm{g} / \mathrm{mL}$; Sigma Aldrich, Merck)

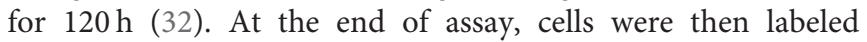
for anti-CD3 APC (MEM-57) and anti-CD4 PE (RPAT4) (BD Biosciences). The Live/Dead Fixable Cell Stain Kit was added to the assay according to the manufacturer's instructions. Cells were then washed twice with PBS and resuspended in $200 \mu \mathrm{L}$ of $4 \%$ Formaldehyde-PBS to proceed to flow cytometry analysis as above-mentioned.

\section{Cytokines Measurement in Culture Supernatants}

IL-1 $\beta$, IL-18, TNF- $\alpha$, and IL-12p70 were measured in MDDC culture supernatants by ELISA according to the manufacturers' protocols (Biolegend for IL-1 $\beta$; IL-18, TNF; eBioscience for IL12p70). Data were reported as $\mathrm{pg} / \mathrm{mL}$. 


\section{Caspase-1 Activity Assay}

The detection of caspase-1 activity in MDDC was measured with the FAM FLICA Caspase-1 Assay Kit (Immunochemistry Technologies) and flow cytometry according to the manufacturer's protocol. Briefly, $10 \mu \mathrm{L} 30 \mathrm{x}$ FLICA was added to $2 \times 10^{5} \mathrm{MDDC}$ in $300 \mathrm{~mL}$ and cells incubated for $1 \mathrm{~h}$ at $37^{\circ} \mathrm{C} 5 \% \mathrm{CO}_{2}$. The Live/Dead Fixable Cell Stain Kit was used. Cells were then washed twice with PBS and resuspended in $200 \mu \mathrm{L}$ of $4 \%$ Formaldehyde-PBS to proceed to flow cytometer analysis as above-mentioned. Live MDDC were gated based on their forward (FSC) and side light scatter (SSC). Histograms for one representative experiment was reported in Supplementary File 3.

\section{Inflammasome Genes Expression Analysis}

Total RNA was isolated from $2 \times 10^{5}$ MDDC using the RNAqueous-Micro kit (Ambion, Thermo Fisher Scientific) according to manufacturer's protocol and quantified using Nanodrop N-1000 (Agilent). $0.5 \mu \mathrm{g}$ of total RNA was converted into cDNA using Superscript III RT kit and random primers (Invitrogen, Thermo Fisher Scientific). NLRP1 (hs00248187), NLRP3 (hs00366465), NAIP (hs03037952), NLRC4 (hs00368367), CASP1 (hs00354836), IL1B (hs01555410), IL18 (hs01038788), CARD8 (hs01088221), BRCC3 (hs02386484), and NEDD8 (hs01921826) genes were amplified using TaqMan ${ }^{\circledR}$ gene-specific assays (Applied Biosystems, Thermo Fisher Scientific) and qPCR on the QuantStudio 3.0 Real-Time PCR equipment (Applied Biosystems, Thermo Fisher Scientific). The QuantStudio 3.0 software was used to obtain cycle threshold values (Ct) for relative gene expression analysis according to Fold Change (FC) method (33). Raw expression data (Ct) were normalized with the expression of the housekeeping gene glyceraldehyde3-phosphate dehydrogenase/GAPDH (hs02758991; TaqMan ${ }^{\circledR}$ assay) $(\triangle \mathrm{Ct})$, and the $\mathrm{FC}$ was calculated comparing stimulated and unstimulated $(\mathrm{UN})$ conditions $\left(\mathrm{FC}=2^{-\Delta \Delta \mathrm{Ct}} ; \Delta \Delta \mathrm{Ct}=\right.$ $\Delta \mathrm{Ct}_{\text {stimulated }}-\Delta \mathrm{Ct}_{\mathrm{UN}}$ ). Alternatively, the basal (constitutive) gene expression was calculated as $2^{-\Delta \mathrm{Ct}}$.

\section{miR-223 Expression Analysis}

Total RNA was isolated from $2 \times 10^{5}$ MDDC by mirVana ${ }^{\mathrm{TM}}$ miRNA Isolation Kit (Ambion, Thermo Fisher Scientific) according to the manufacturer's instructions. $0.5 \mu \mathrm{g}$ of total RNA were converted into cDNA using kit TaqMan ${ }^{\mathrm{TM}}$ MicroRNA Reverse Transcription and miRNA-specific primers (Applied Biosystems, Thermo Fisher Scientific). miR-223 was amplified using TaqMan ${ }^{\circledR}$ miR-specific assays (TM:002098; Applied Biosystems, Thermo Fisher Scientific) and qPCR on the QuantStudio 3.0 Real-Time PCR equipment. The QuantStudio 3.0 software was used to obtain cycle threshold values $(\mathrm{Ct})$ for relative gene expression analysis according to Fold Change (FC) method (33). Raw expression data (Ct) were normalized with the expression of and non-coding small RNA control U6 (TM:001973; TaqMan ${ }^{\circledR}$ assay) ( $\Delta \mathrm{Ct}$ ), and the FC was calculated comparing stimulated and unstimulated (UN) conditions $\left(\mathrm{FC}=2^{-\Delta \Delta \mathrm{Ct}} ; \Delta \Delta \mathrm{Ct}=\Delta \mathrm{Ct}_{\text {stimulated }}-\Delta \mathrm{Ct}_{\mathrm{UN}}\right)$. Alternatively, the basal (constitutive) gene expression was calculated as $2^{-\Delta \mathrm{Ct}}$.

\section{Detection of "Specks" Formation}

Detection of inflammasome "specks" formation was performed by confocal microscopy and immunofluorescence, as previously described (34). Briefly, $2 \times 10^{5}$ MDDC were cultured in 16wells chamber slides (Thermo Fisher Scientific) and stimulated with $5 \mu \mathrm{g} / \mathrm{mL}$ FLG or $1 \mu \mathrm{g} / \mathrm{mL}$ LPS for $24 \mathrm{~h}$ at $37^{\circ} \mathrm{C} 5 \%$ $\mathrm{CO}_{2}$ with or without $1 \mathrm{mM}$ ATP. Cells were then fixed and permeabilized with Cytofix/Cytoperm reagent (BD Biosciences) for $30 \mathrm{~min}$ at $37^{\circ} \mathrm{C} 5 \% \mathrm{CO}_{2}$, and incubated with primary antibody for NLRP3 (1:100 mouse anti-human NLRP3, Abcam) and/or NLRC4 (1:200 rabbit anti-human NLRC4; Biolegend) overnight at room temperature. Fluorescent secondary antibodies (Alexa 488-conjugated goat-anti-mouse IgG1, or Alexa 647-conjugated goat-anti-rabbit IgG1; Biolegend) were then added for $1 \mathrm{~h}$. Finally, cells were washed and fixed to image acquisition at DMi8 confocal laser scanning microscope (Leica). 4',6-Diamidine-2'phenylindole dihydrochloride (DAPI; Sigma-Aldrich, Merck) was used for nuclear counterstaining. ImageJ software and related plugins (National Institutes of Health) were used for image processing. The counting of NLRP3+ and NLRC4+ specks in MDDC was performed manually by observing specks formation within the cells (34), and through the ImageJ software by calculating the corrected total cellular fluorescence (CTCF) for each marker as integrated density-(area of selected cell $\times$ mean fluorescence of background readings) (35).

\section{NLRC4 and NLRP3 Silencing}

Pre-validated shRNA for human NLRC4 and NLRP3 was obtained from MISSION ${ }^{\circledR}$ shRNA Plasmid DNA (SigmaAldrich, Merck). The shRNAs for NLRP3 and NLRC4 used in the study are listed in Supplementary File 4. $2 \times 10^{5}$ MDDC were transduced using with the same amounts of lentiviral particles encoding non-targeting control or gene-specific shRNA in the presence of SIV3+ VLP for $48 \mathrm{~h}$. Thereafter, cells were treated with $5 \mu \mathrm{g} / \mathrm{mL}$ FLG or $1 \mu \mathrm{g} / \mathrm{mL}$ LPS for $24 \mathrm{~h}$. The shRNA knockdown efficiency of the target protein in lentivirus-transduced cells was assessed by gene expression (Supplementary File 5). The concentrations of IL-1 $\beta$ in cell culture supernatants was measured by ELISA.

\section{Data Analysis}

All data were collected and analyzed from at least three independent experiments. Normality test was applied to the data, and parametric or non-parametric analysis was used accordingly to compare two or more data sets as specified for each graph. The level of significance was $p<0.05$. Calculations were performed using the statistical software package GraphPad Prism 7.0.

\section{Biosecurity and Institutional Safety Procedures}

All research was performed following the guidelines of biosecurity and safety of Institute of Biomedical Science (ICB/USP). 


\section{RESULTS}

\section{Flagellin Similarly Activates MDDC From HIV-Infected Patients and Healthy Donors}

MDDC were treated with $5 \mu \mathrm{g} / \mathrm{mL}$ FLG for $24 \mathrm{~h}$ and phenotypic profile, TNF and IL-12 secretion as well as $\mathrm{CD} 4^{+} \mathrm{T}$ lymphocytes activation in co-culture experiments were assessed based on previously published protocols $(31,32)$.

FLG activates MDDC, both HIV-DC and HD-DC, as indicated by the increase of co-stimulatory molecules, cytokines release and $\mathrm{CD} 4^{+} \mathrm{T}$ lymphocytes activation (Figure 1).

As expected, FLG induced the up-regulation of HLA-DR ( $95.83 \pm 0.68 \%$ positive cells) compared to untreated cells (UN: $77.5 \pm 4.4 \%$ positive cells) and the significant increase of CD40 (FLG: $39.8 \pm 3.7 \%$, vs. UN: $7.8 \pm 2.0 \%$ positive cells; $p=3$ $\times 10^{-5}$ ) in HD-DC, but not of CD86, which appeared to be decreased in HD-DC+FLG compared to untreated cells (FLG: $62.8 \pm 4.3 \%$, vs. UN: $91.1 \pm 2.9 \%$ positive cells; $p=0.001$ ) (Figure 1A). However, this result could be due to a previously reported positive feedback mechanism and not to a negative effect of FLG (36). A significant augment of HLA-DR (FLG: 83.5 $\pm 6.1 \%$, vs. UN: $49.2 \pm 9.5 \%$ positive cells; $p=0.006)$ and CD40 (FLG: $48.7 \pm 5.4 \%$, vs. UN: $17.4 \pm 1.7 \%$ positive cells; $p=0.020)$ was observed in HIV-DC challenged with FLG. The expression of CD86 did not change in treated or untreated cells (Figure 1A).

It is interesting to emphasize that the entity of surface markers expression did not significantly differ between HIVDC and HD-DC in both untreated or treated conditions (Figure 1A). Even if we observed lower viability in HIV-DC compared to HD-DC, this difference did not result statistically significant $(p>0.999)$.

FLG induced the secretion of a good and similar amount of TNF in HD-DC and HIV-DC $(p<0.05)$ (Figure 1B). On the other hand, the production of IL-12 differs between HD-DC and HIV-DC $(p=0.029)$ : while HD-DC produced significant level of IL-12 in response to the molecular pattern (FLG: 212.7 $\pm 53.1 \mathrm{pg} / \mathrm{mL}$, vs. UN: $\left.50.5 \pm 2.9 \mathrm{pg} / \mathrm{mL} ; p=7 \times 10^{-4}\right)$, the induction of cytokine appeared to be less pronounced in HIVDC (FLG: $63.9 \pm 6.9 \mathrm{pg} / \mathrm{mL}$, vs. UN: $38.2 \pm 12.1 \mathrm{pg} / \mathrm{mL} ; p>$ 0.05) (Figure 1C).

Altogether these data indicate that FLG is able to activate HIV-DC in a similar way to that seen for HD-DC.

To test whether FLG-treated MDDC are able to induce a properly adaptive immunity response, a MDDC/lymphocytes coculture assay was performed using autologous cells as previously described $(31,32)$. Lymphocytes alone were used as a negative control (Neg) (Figures 1D,E).

A significant increment of IFN- $\gamma^{+} \mathrm{CD} 4^{+} \mathrm{T}$ cells was observed in healthy donors (FLG: $12.9 \pm 5.5 \%$ vs. UN: $1.3 \pm 0.4 \%$ positive cells; $p=0.022$ ) as well as in HIV-infected individuals (FLG: $9.6 \pm 1.8 \%$ vs. UN: $0.1 \pm 0.1 \%$ positive cells; $p=$ $0.014)$. Of note, the percentage of IFN- $\gamma^{+} \mathrm{CD} 4^{+} \mathrm{T}$ cells after FLG treatment was similar in healthy donor and patients $(p>0.999)$. Negative control resulted similar to untreated co-cultures $(p>$ 0.05 ) (Figure 1D), emphasizing that the increasing percentage of positive cells is not an artifact.
Moreover, FLG-treated MDDC were able to induce a significant proliferation of $\mathrm{CD} 4^{+} \mathrm{T}$ lymphocytes in healthy donors (FLG: $51.0 \pm 12.1 \%$, vs. UN: $3.7 \pm 0.9 \%$ positive cells; $p=0.026$ ) and patients (FLG: $24.3 \pm 2.8 \%$, vs. UN: $3.5 \pm$ $0.8 \%$ positive cells; $p=0.038$ ), even if in a lesser extent in patients compared to $\operatorname{HD}(p=0.004)$. Negative control presented a proliferation rate similar to untreated co-cultures $(p>0.05)$ (Figure 1E).

It is interesting to underline that the limited percentage of positive cells in this type of assay is in accord with previously published data for autologous MDDC and T cells co-culture both in healthy donors (32) and even in HIV-infected patients (31) treated with unspecific stimuli (mitogens). Moreover, despite its limited entity, the activation of lymphocytes is consequence of MDDC stimulation as in the absence of MDDC (negative control) mitogens cannot activate T cells (Figures 1D,E).

Taking in account the activation status of FLG-treated HIV-DC (Figures 1A-C) together with their ability to induce lymphocytes activation (Figures 1D,E), we clearly demonstrated that FLG is able to activate HIV-DC similarly to what observed for HD-DC. It is interesting to emphasize that, on the contrary, we have previously shown that HIV-DC did not properly respond to bacterial LPS (14).

\section{Flagellin, but Not LPS, Induces Comparable Inflammasome Activation in MDDC From HIV-Infected Patients and Healthy Donors}

We then investigated the ability of flagellin to stimulate inflammasome in MDDC by the meaning of inflammasome cytokines production and caspase-1 activity. LPS alone or in combination with ATP was added to the assay as a positive control for inflammasome or NLRP3 inflammasome activation, respectively (26) (Figure 2). A time-course assay treating MDDC with $5 \mu \mathrm{g} / \mathrm{mL}$ FLG or $1 \mu \mathrm{g} / \mathrm{mL}$ LPS was performed to determine the best experimental time for IL-1ß detection in this model, (Supplementary File 6), and selected $24 \mathrm{~h}$ for all the experiments.

FLG induced a significant IL-1ß release in HD-DC (155.3 \pm $20.7 \mathrm{pg} / \mathrm{mL})$, compared to unstimulated cells $(4.0 \pm 1.9 \mathrm{pg} / \mathrm{mL} ; p$ $<0.0001)$ and similarly to LPS $(132.4 \pm 9.9 \mathrm{pg} / \mathrm{mL} ; p<0.0001)$. The treatment with LPS+ATP resulted in a significant increase of IL- $1 ß$ release compared to LPS ( $p=0.002)$, indicating a proper response of NLRP3 inflammasome in HD-DC (Figure 2A).

In HIV-DC, the entity of IL- $1 ß$ production resulted lower than in HD-DC but significantly augmented compared to resting cells (FLG: $121.3 \pm 34.3 \mathrm{pg} / \mathrm{mL}$; vs. UN: $18.3 \pm 9.3 \mathrm{pg} / \mathrm{mL} ; p$ $\left.=2 \times 10^{-4}\right)$ and also to LPS-treated cells $(84.4 \pm 17.5 \mathrm{pg} / \mathrm{mL}$; $p=0.002)$. However, ATP did not alter LPS-induced IL- $1 \beta$ production $(p>0.05)$ (Figure 2A), confirming the previously observed dysregulation of NLRP3 inflammasome in MDDC from HIV-infected patients (14).

In a similar way, FLG also induced significantly IL-18 release in HD-DC (FLG: $91.1 \pm 19.3 \mathrm{pg} / \mathrm{mL}$, vs. UN: $12.8 \pm 6.1 \mathrm{pg} / \mathrm{mL} ; p$ $=0.018$ ) and at lower extent in HIV-DC (FLG: $50.5 \pm 5.6 \mathrm{pg} / \mathrm{mL}$, vs. UN: $2.9 \pm 1.5 \mathrm{pg} / \mathrm{mL} ; p=0.009)$. HD-DC better respond to LPS and LPS+ATP than HIV-DC also in term of IL-18. There 


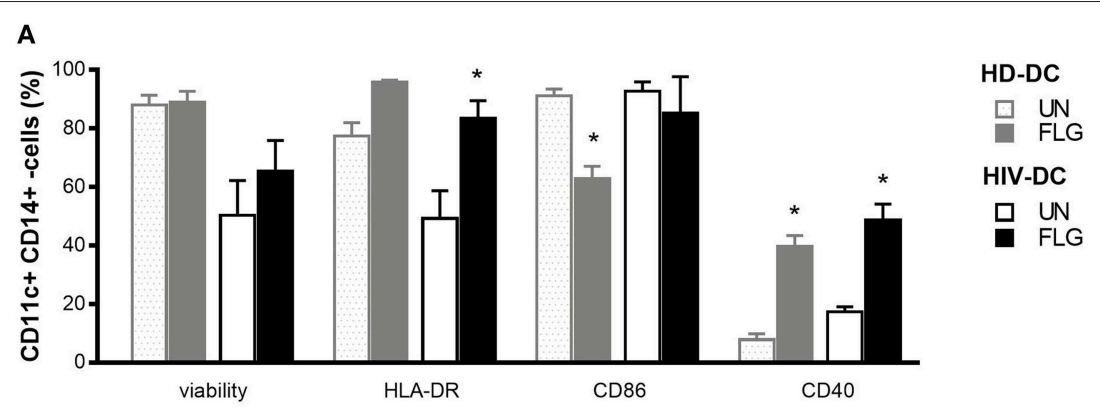

B

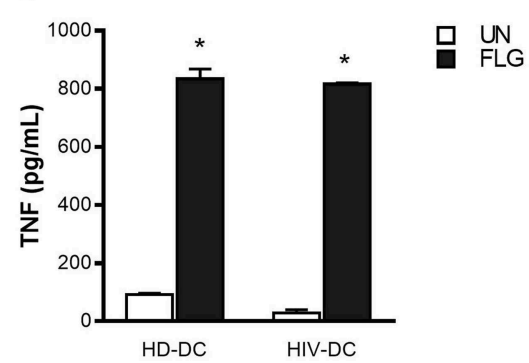

D

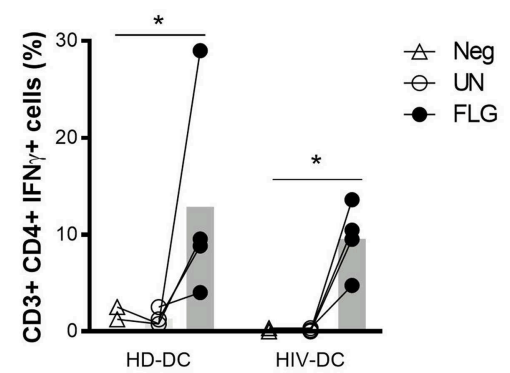

C

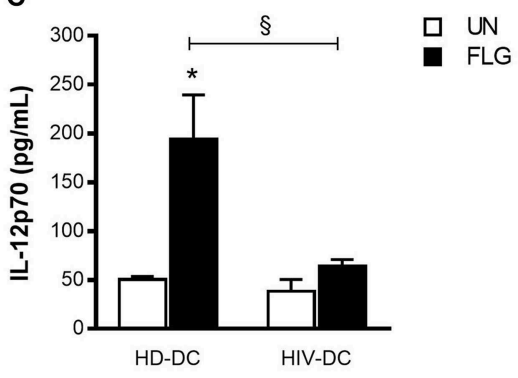

E

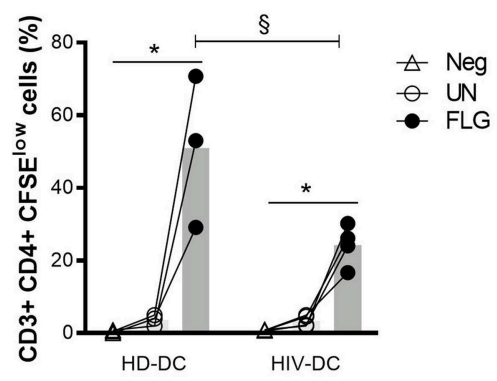

FIGURE 1 | Flagellin similarly activates HIV-DC and HD-DC. $2 \times 10^{5}$ MDDC from healthy donors (HD-DC; $\left.n=5\right)$ and HIV-infected patients (HIV-DC; $\left.n=5\right)$ were stimulated with $5 \mu \mathrm{g} / \mathrm{ml}$ flagellin (FLG) for 24 hours. Viability, expression of characteristic DC surface markers (A) as well as TNF (B) and IL-12p70 (C) secretion were analyzed and compared between untreated (UN) and stimulated (FLG) conditions as well between HD-DC and HIV-DC groups $0.4 \times 10^{5}$ FLG-treated MDDC were cultured with $4 \times 10^{5}$ autologous lymphocytes (MDDC/lymphocytes ratio: 1/0) for 96 hours to detect IFN- $\gamma$ production in CD4 ${ }^{+} \mathrm{T}$ lymphocytes (percentage of CD3 +

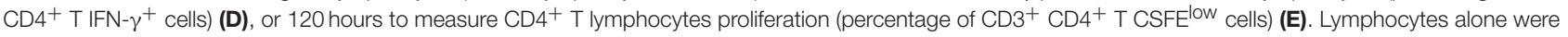
used as a negative control (Neg). Data are reported as mean \pm standard error. Multiple $t$-test (A) and Two-Way ANOVA test (B-E) were applied to compare conditions within a group (HIV-DC or HD-DC; $\left.{ }^{*} p<0.05\right)$ and between groups (HIV-DC vs. HD-DC; $\left.{ }^{\S} p<0.05\right)$.

were no statistical differences in the production of IL-18 between HD- and HIV-DC (Figure 2B).

Inflammasome cytokines release revealed that FLG is able to induce complex activation in MDDC from healthy as well as HIV-infected individuals. Accordingly, FLG increased caspase1 activity in HD-DC (FLG: $6.8 \pm 2.0 \%$, vs. UN: $0.3 \pm$ $0.0 \%$ positive cells) and in HIV-DC (FLG: $6.9 \pm 0.7 \%$, vs. UN: $3.5 \pm 0.5 \%$ positive cells). HIV-DC presented a constitutively activated caspase-1, however a lower activation in response to LPS+ATP compared to HD-DC, once more emphasizing the specific dysregulation of NLRP3 pathway (Figure 2C). Even if these differences did not reach statistical significance $(p=0.07)$, we underline that caspase- 1 activity accompanies above-mentioned cytokines data, and that this is the first study showing a tendency in caspase-1 activation defect in MDDC from HIV-infected individuals. Although other studies have reported statistically significant differences in caspase- 1 activity in healthy donors and HIV-infected patients, those results referred to lymphoid compartment or peripheral blood mononuclear cells, while little is known in myeloid cells $(37-40)$.

\section{Flagellin Induces Inflammasome Activation by Stimulated NAIP/NLRC4 and NLRP3 Receptors in HD-DC, but Not in HIV-DC}

Once assessed that FLG is able to induce inflammasome activation in MDDC, we therefore tried to depict the pathways involved in complex formation and to detect any differences between HD-DC and HIV-DC. 

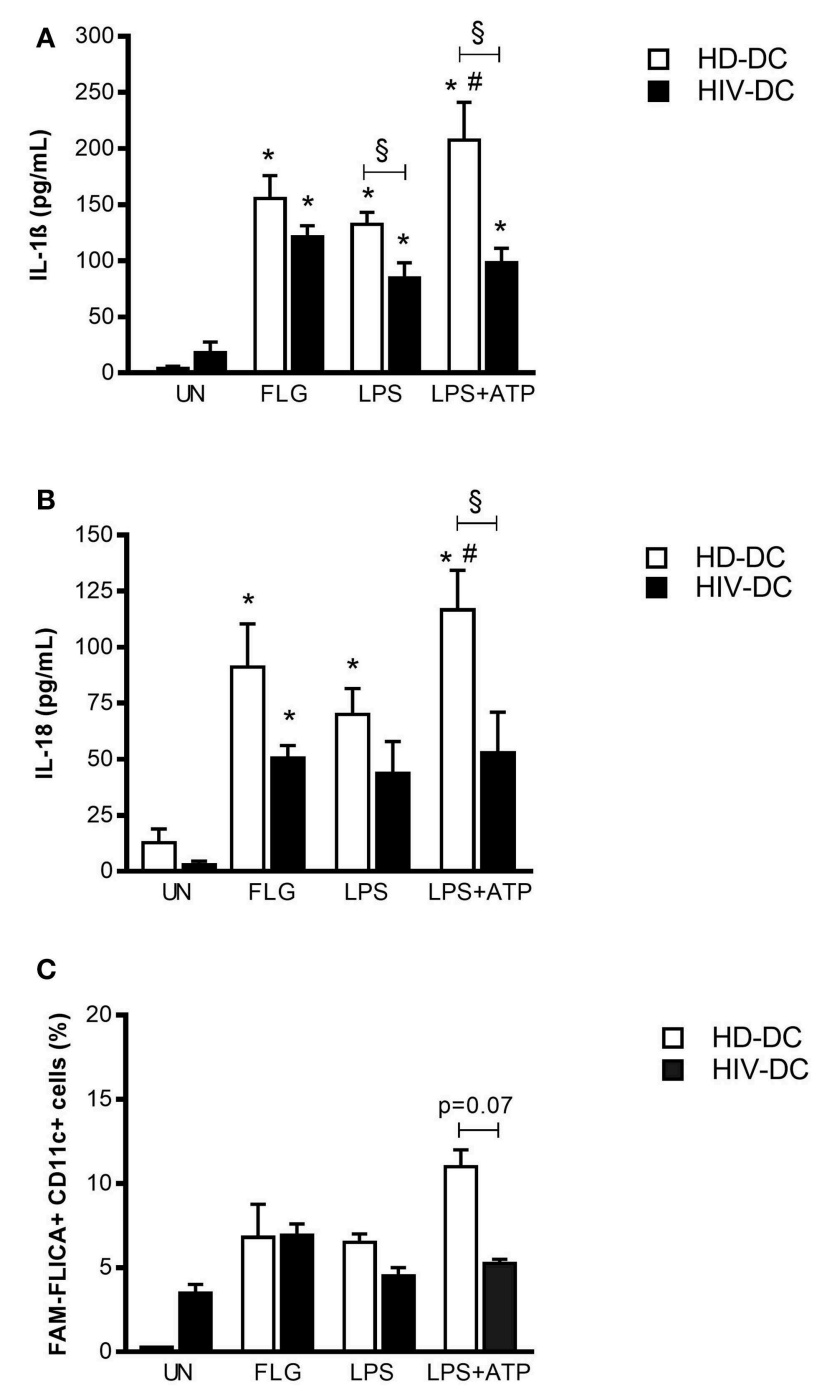

FIGURE 2 | Flagellin induces better inflammasome activation in HIV-DC than LPS. $2 \times 10^{5}$ MDDC from healthy donors (HD-DC; $n=20$ ) or HIV-infected patients (HIV-DC; $n=20$ ) were stimulated with $5 \mu \mathrm{g} / \mathrm{mL}$ flagellin (FLG) for 24 hours. $1 \mu \mathrm{g} / \mathrm{mL}$ LPS for 24 hours, or $1 \mu \mathrm{g} / \mathrm{mL}$ LPS for 24 hours plus $1 \mathrm{mM}$ ATP for more 15 minutes were used as positive control for the activation of inflammasome and NLRP3 inflammasome, respectively. Culture supernatants were used to measure IL-1 $\beta$ (A) and IL-18 (B) concentration $(\mathrm{pg} / \mathrm{mL})$. Cells were harvested for analysis of caspase- 1 activity by FAM-FLICA assay and flow cytometry. Percentage of FAM-FLICA+CD11C ${ }^{+}$cells were reported for FLG-treated (FLG) and untreated (UN) MDDC (C). Data are represented as mean \pm standard error. Two-Way ANOVA test was applied to compare conditions within a group (HIV-DC or HD-DC; ${ }^{*} p<0.05$; LPS+ATP vs. LPS: $\# p<0.05)$ and between groups (HIV-DC vs. HD-DC; $\left.{ }^{\S} p<0.05\right)$.

Gene expression analysis revealed that HIV-DC presents a significant higher constitutive expression of $I L 1 B$ and $I L 18$ compared to HD-DC. NLRP3 also resulted increased even if not in a statistically significant way, while the level of NAIP and NLRC4 was similar between MDDC (Figure 3A).

When the effect of flagellin was evaluated in genes modulation, we observed a revealed a different expression profile in HD-DC and HIV-DC at all the analyzed time-points $(3,8,18$, and $24 \mathrm{~h}$ ) (Figure 3B).

In particular, we focused our attention on the two receptors NLRP3 and NLRC4. While, as expected, FLG induces NLRC4 gene modulation in HD-DC and HIV-DC (Figure 3C), NLRP3 appeared to be defective in HIV-DC, as FLG was able to induce NLRP3 expression in HD, but not in HIV-DC (Figure 3D), according to our previously published data (14).

The dysregulation observed for NLRP3 could be due to an imbalance of inhibitor and activator signals. NLRP3 is tightly regulated by endogenous proteins CARD8 (41), BRCC3 (42) and NEDD8 (43), and by miR-223 (44). Interestingly, the basal expression of CARD8 and BRCC3, as well as of miR223, resulted significantly augmented in HIV-DC compared to HD-DC (Figure 3E), suggesting a possible cause of low responsiveness of NLRP3. Moreover, taking in account that IFNI also contributes to the negative regulation of $\operatorname{NLRP3}(29,30)$ and that HIV-infected patients are known to present high level of circulating IFN-I (45-47), we shown that the treatment of HDDC with IFN-a significantly reduced IL- $1 ß$ release specifically in LPS + ATP treated cells up to cytokine level observed in HIV-DC (Figure 3F), emphasizing the inhibitory role of IFN-I on NLRP3 and suggesting that this could be another cause of a specific NLRP3 defect in HIV-DC.

According to our initial hypothesis, flagellin appears to be able to by-pass this defect of NLRP3 in HIV-DC, and at the same time our results have shown the involvement of both NLRC4 and NLRP3 receptors in HD-DC response to flagellin.

This hypothesis of a "two-receptors" mechanism is supported also by inflammasome "specks" detection through immunofluorescence staining of NLRP3 and NLRC4 (Figure 4). NLRC4+ specks were evidenced in confocal imagines of FLGtreated HD-DC (Figure 4A) and HIV-DC (Figure 4B). NLRP3+ specks resulted more in FLG-treated HD-DC (Figure 4A) than in HIV-DC (Figure 4B). In general NLRC4 and NLRP3 staining localized in the same cells. By the use of CTCF index, we showed that FLG significantly induced both NLRC4+ and NLRP3+ specks in HD-DC (FLG vs. UN: $p<0.0001$ ) (Figure 4C). On the other hands, in HIV-DC FLG induced preferentially NLRC4+ specks (CTCF FLG vs. UN: $p=0.0001$ ) and at lesser extent NLRP3 + specks $(p>0.05)$ (Figure 4D). These findings demonstrated that in healthy donor cells, FLG not only activates inflammasome through the expected NAIP/NLRC4 pathway but also through the NLRP3 one.

To better investigate the involvement of NAIP/NLRC4 and NLRP3 in response to FLG in our model, we evaluated the IL$1 ß$ production in FLG-treated MDDC previously incubated with $10 \mu$ M MCC-950, a specific NLRP3 inhibitor (27), or with $10 \mu \mathrm{M}$ parthenolide/PTD, a large spectrum inflammasome inhibitor (28) (Figures 5A,B).

MCC-950 and PTD significantly inhibited IL-1ß production in FLG-treated HD-DC (78 and $90 \%$ of inhibition, respectively; $p<0.05$ ), as well as LPS+ATP-treated cells (78 and $90 \%$ of inhibition, respectively; $p<0.05$ ), and partially LPS-induced inflammasome activation (78 and $90 \%$ of inhibition, respectively; $p<0.05$ ) (Figure 5A), due to the contribution of other pathway in inflammasome activation by LPS (48). 
A

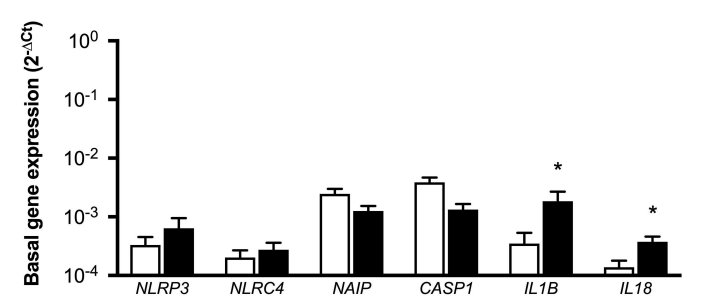

B

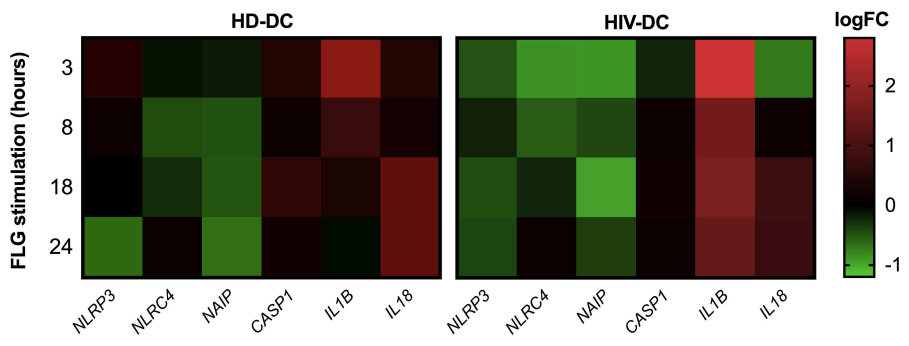

C

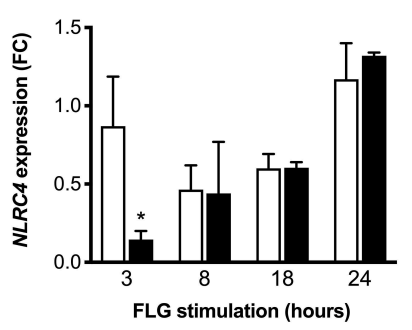

E

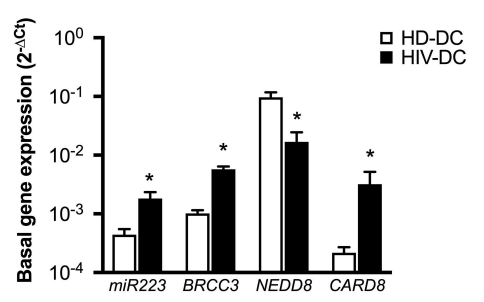

D

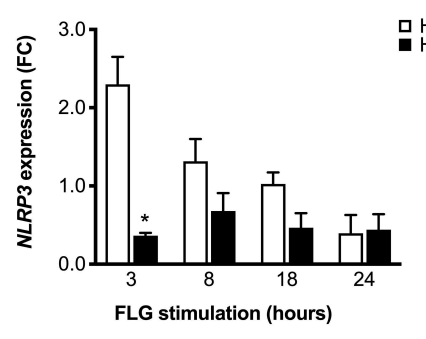

$\mathbf{F}$

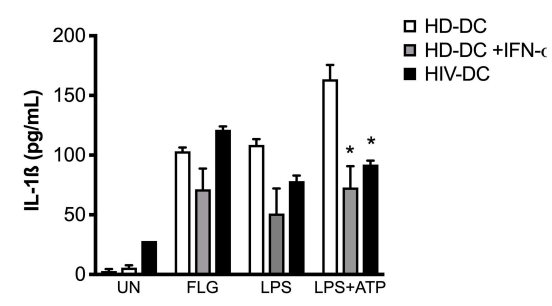

FIGURE 3 | NLRC4 and NLRP3 are differentially involved in flagellin activation in HD-DC and HIV-DC. $2 \times 10^{5}$ MDDC from healthy donors (HD-DC; $n=5$ ) or HIV-infected patients (HIV-DC; $n=5$ ) were stimulated with $5 \mu \mathrm{g} / \mathrm{ml}$ flagellin (FLG) for $3,8,18$, and 24 hours. Cells were harvested for total RNA isolation and evaluation of relative gene expression by qPCR (A-E). (A) Basal gene expression of NLRP3, NAIP, NLRC4, CASP1, IL18, and IL1B was expressed as $2^{-\triangle C t}$. (B) FLG-induced expression of NLRP1, NLRP3, NLRC4, NAIP, CASP1, IL1B, and IL18 genes was calculated as $2^{-\triangle \triangle C t}$ (fold-change, FC) and reported as logFC in a heat-map graph for HD-DC and HIV-DC. (C) FC values for NLRC4 are compared between HD-DC and HIV-DC at all the time-points. (D) FC values for NLRP3 are compared between HD-DC and HIV-DC at all the time-points. (E) Basal gene expression of miR223, BRCC3, NEDD8, and CARD8 was expressed as $2^{-\Delta C t}$. (F) $2 \times 10^{5} \mathrm{MDDC}$ from healthy donors (HD-DC; $n=3$ ) were pre-treated with $1,000 \mathrm{UI} / \mathrm{mL}$ of IFN- $\alpha-2 \mathrm{~b}$ (Schering-Plough) for $18 \mathrm{~h}$ and then with $5 \mu \mathrm{g} / \mathrm{ml}$ flagellin (FLG) or LPS $1 \mu \mathrm{g} / \mathrm{mL} \mathrm{LPS}$ for 24 hours, or $1 \mu \mathrm{g} / \mathrm{mL}$ LPS for 24 hours plus $1 \mathrm{mM}$ ATP for more 15 minutes. IL-1B concentration was measured in culture supernatants of HD-DC with and without IFN- $\alpha$-2b pre-treatment and compared with HIV-DC $(n=3)$ stimulated with FLG. Data are represented as mean \pm standard error. Multiple $t$-test was applied to compare HD- and HIV-DC in (A,C-E). Kruskall-Wallis test was applied to compare HD-DC, HD-DC + IFN- $\alpha-2 b$, and HIV-DC sets in (F) $\left({ }^{*} p<0.05\right)$.

On the other side, MCC-950 was not able to significantly reduce cytokine release in HIV-DC stimulated with FLG (48\% of inhibition; $p>0.05)$, LPS (48\% of inhibition; $p>0.05)$ or LPS +ATP (48\% of inhibition; $p>0.05)$ (Figure 5B). Accordingly, in the presence of MCC-950 a reduction not significantly of NLRP3+ specks was observed in HIV-DC (Supplementary File 7). PTD similarly inhibited IL-1 $\beta$ production in both FLG-treated HIV-DC $(84 \%$ of inhibition $p=0.002)$, LPS or LPS+ATP-treated HIVDC (84\% of inhibition; $p=0.002)$, as expected due to 

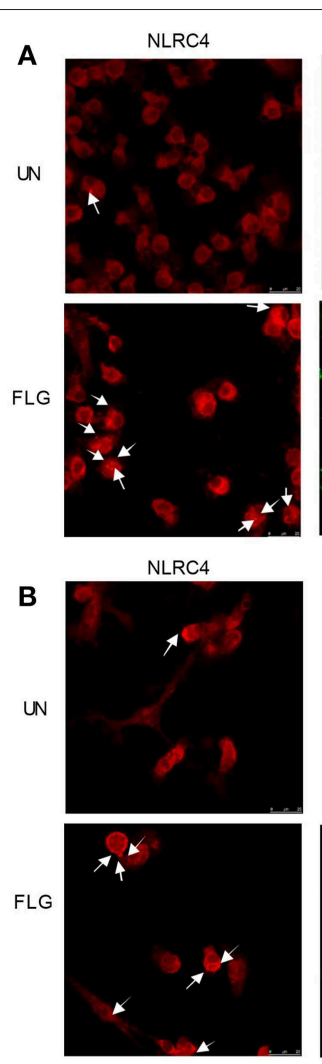

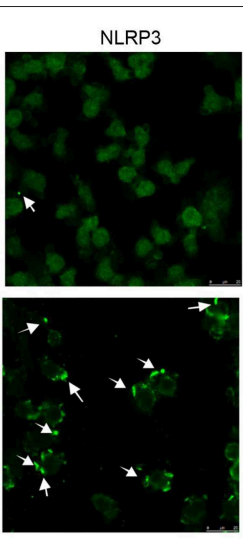

NLRP3
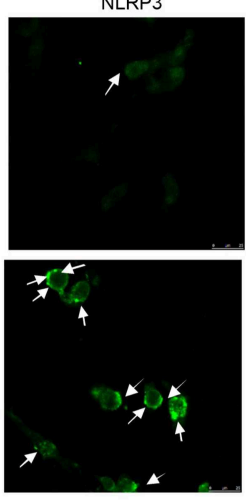
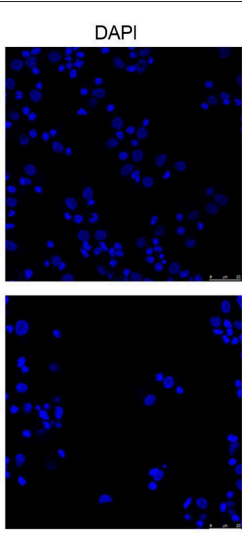

DAPI
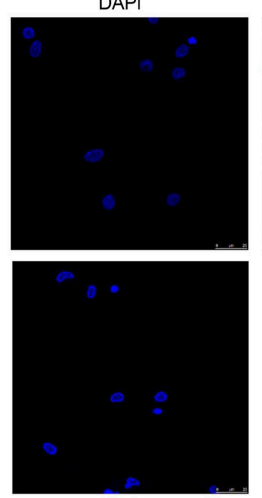

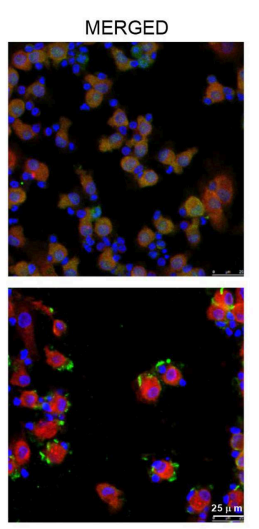

C

MERGED
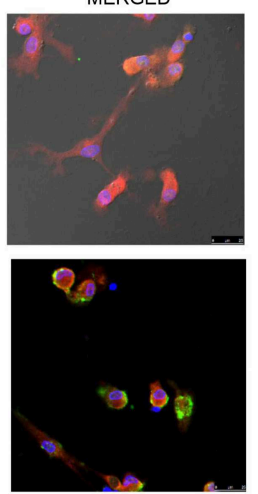

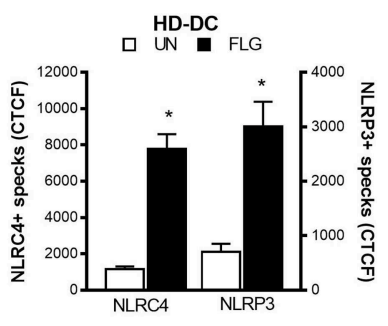

D

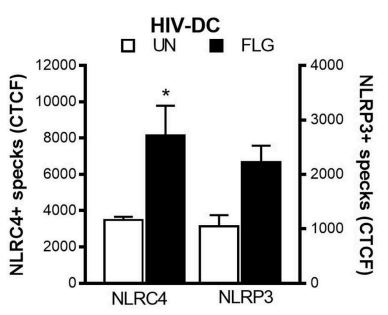

FIGURE 4 | Flagellin induces NLRC4+ and NLRP3+ specks formation in MDDC. $2 \times 10^{5}$ MDDC from healthy donors (HD-DC; $n=3$ ) or HIV-infected patients (HIV-DC; $n=3$ ) were cultured in 16 -wells chamber slides and stimulated with $5 \mu \mathrm{g} / \mathrm{mL}$ FLG or $1 \mu \mathrm{g} / \mathrm{mL}$ LPS for 24 hours at $37^{\circ} \mathrm{C} 5 \%$ CO 2 with or without $1 \mathrm{mM} \mathrm{ATP}$ for more 15 minutes. Mouse anti-human NLRP3 and rabbit anti-human NLRC4 antibodies and fluorescent secondary antibodies (Alexa 488-conjugated goat-anti-mouse IgG1; Alexa 647-conjugated goat-anti-rabbit lgG1) were used to label NLRP3+ and NLRC4+ specks, respectively. DAPI was used to counterstain nuclei. Images acquisition was performed using a DMi8 confocal laser scanning microscope. A representative experiment (magnification: $63 x$ ) was reported for HD-DC (A) and HIV-DC (B). Arrows indicated NLRC4+ or NLRP3+ specks. (C,D) CTCF index for NLRP3+ and NLRC4+ specks in untreated (UN) and FLG-treated (FLG) MDDC. Data are represented as mean \pm standard error. Mann-Whitney test was applied to compare UN and FLG conditions in (C,D) $\left({ }^{*} P<0.05\right)$.

the caspase-1 and NF-kB dependency for FLG-induced response (49), as well as for LPS-mediated one (48). These data confirm the greater involvement of NLRP3 in response to FLG in healthy donors compared to HIV-infected individuals.

Then we compared the differences in IL-1ß release in FLGtreated MDDC following NLRC4 or NLRP3 shRNA knockdown (Figures 5C,D). In NLRC4 shRNA-transduced MDDC, FLG induced a lower level of IL-1ß production compared to untreated cells both in HD-DC (Figure 5C) and in HIV-DC (Figure 5D). In NLRP3 siRNA-transducted MDDC, FLG induced a lower level of IL-1ß compared to untreated cells in HD-DC (Figure 5C), however this effect was not observed in HIV-DC (Figure 5D). These data are in accord with above-reported effect of chemical NLRP3 inhibitor MCC-950 (Figures 5A,B).

Altogether these findings allow us to suggest that FLG activates the inflammasome in human MDDC through the induction of NAIP/NLRC4 and NLRP3 receptors; the contribution of NLRP3 in FLG-signaling is less pronounced in HIV-DC due to the well-known "exhausted" profile of these cells (50).

\section{DISCUSSION}

A number of microbial components have been proposed as alternative adjuvants to augment the immune responses of poorly immunogenic vaccines and/or of not fully immunocompetent individuals. Emerging evidence pointed out the possible use of bacterial flagellin in this context, firstly in mice [as extensively revised in Hajam et al. (17)], but also in a human clinical trial of prophylactic vaccine (23). Studies in mice show the stimulatory capacity of flagellin to induce both humoral and cellular immune responses when implied together with pathogen' antigens as adjuvant $(51,52)$ or in cancer immunotherapy (53).

Taking in account that, even in ART treatment, HIV-infected individuals continue to experience immune dysfunction, leading, among others side effects, to a deficient vaccine response (9), the necessity of new vaccine strategy in this population appear to be urgent.

Using the in vitro model of peripheral blood monocytesderived-dendritic cells developed for HIV-infected patient's immunotherapy by Lu and collaborators (54), we demonstrated 

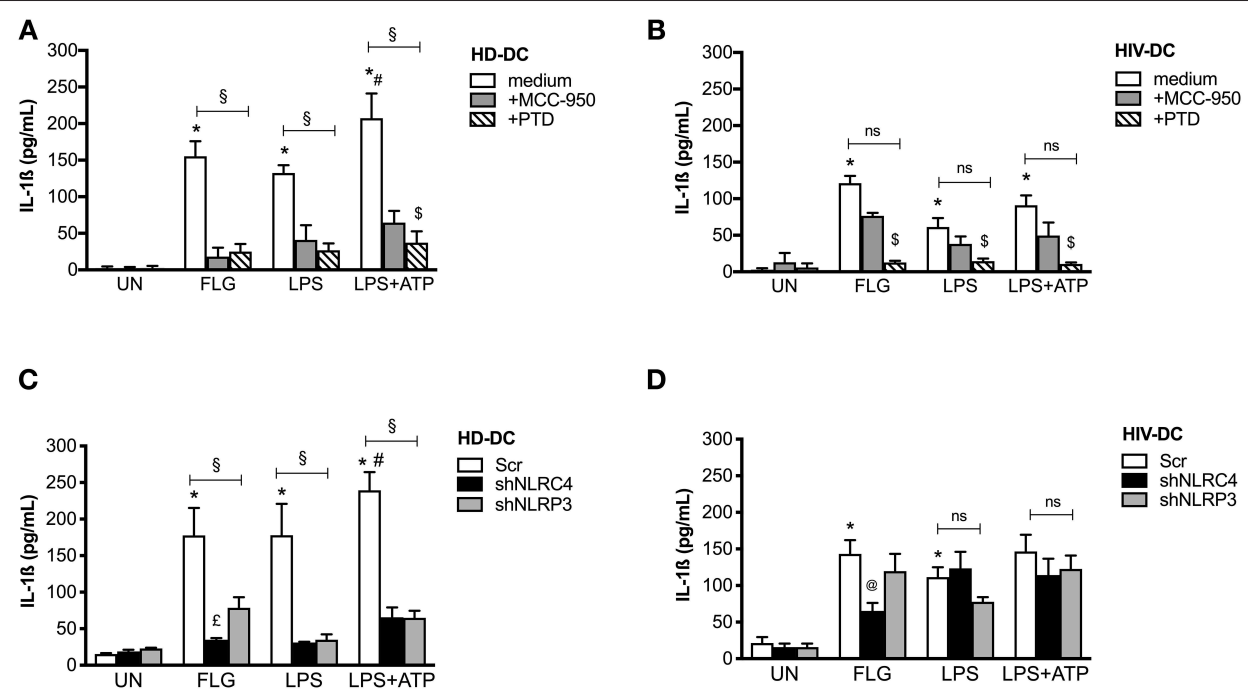

FIGURE 5 | Flagellin significantly induces NLRC4 but not NLRP3 in HIV-DC. $2 \times 10^{5}$ MDDC from healthy donors (HD-DC; $\left.n=5\right)$ (A) and HIV-infected patients $(\mathrm{HIV}-\mathrm{DC} ; n=5)(B)$ were pretreated with $10 \mu \mathrm{M}$ MCC-950 or $10 \mu \mathrm{M}$ parthenolide (PTD), and then stimulated with $5 \mu \mathrm{g} / \mathrm{ml}$ FLG for 24 hours or $1 \mu \mathrm{g} / \mathrm{mL} \mathrm{LPS}$ for 24 hours with or without $1 \mathrm{mM}$ ATP for more 15 minutes. IL-1B concentration was measured in culture supernatants. $2 \times 10^{5} \mathrm{MDDC}$ from healthy donors (HD-DC; $n=3$ ) (C) and HIV-infected patients (HIV-DC; $n=3$ ) (D) were transduced with empty vector (scramble: Scr), shNLRC4 or shNLRP3, and then stimulated with $5 \mu$ g/ml FLG for 24 hours, or $1 \mu \mathrm{g} / \mathrm{mL}$ LPS for 24 hours with or without $1 \mathrm{mM}$ ATP for more 15 minutes. IL-1B concentration was measured in culture supernatants. Kruskal-Wallis test with multi comparison post-test was applied (treated vs. UN: ${ }^{*} p<0.05$; LPS+ATP vs. LPS ${ }^{\#} p<0.05$; within each group: ${ }^{\S} p<0.05 ;+$ MCC-950 vs. + PTD: ${ }^{\$} p$ $<0.05$; shNLRC4 vs. shNLRP3: £p < 0.05; shNLRC4 vs. Scr: @p<0.05).

that flagellin is able to activate MDDC from HIV-infected patients as well as from healthy donors. Previous studies have evidenced the ability of flagellin to activate primary human monocytes, or human pro-monocytic cell line U38 (55), however here we demonstrated that flagellin is able to activate human MDDC considering both the MDDC profile as well as the MDDC-mediated lymphocytes activation (Figure 1), with the exception of IL-12 production which results lower in HIV-DC compared to HD-DC, but in accord with previously published data (56).

Flagellin is sensed by two main innate immune receptors, TLR5 (18) and NAIP/NLRC4 (57-59). While it has been shown that flagellin induces NAIP/NLRC4 inflammasome activation in primary human macrophages and monocytes $(49,60,61)$, little is known about its role in human DC. Despite it has been previously reported that flagellin stimulates IL-1 $\beta$ production in human MDDC (62), any evidence about NLRC4 or NLRP3 pathway in IL-1ß induction have been shown nor hypothesized. Besides the description of these two receptors within inflammasome activation by flagellin, our study also demonstrated for the first time the different contribution of the two receptors in HIV-DC response to flagellin.

As expected, flagellin induces the inflammasome activation through NAIP/NLRC4 both in HD-DC as well as HIV-DC (Figure 2), suggesting that this pathway is still effective in HIV-infected patients, contrary to what seen for NLRP3 (14). Actually, HIV-DC presents a basal increased expression of NLRP3 inhibitory molecules, namely CARD8 (41), BRCC3 (42) and miR-223 (44), compatible with specific inhibition of this receptor (Figure $3 \mathrm{E})$.
While the low rate of NLRP3 response in HIV-DC has been attributed to the chronic inflammation of HIVinfected patients, consequent of HIV-1 persistence, endogenous viruses reactivation (i.e., herpes simplex virus), immune system exhaustion, increased intestinal permeability and microbial translocation (mainly LPS) and antiretroviral drugs cytotoxicity $(15,63)$ and taking in account that flagellate bacteria also could be present in gut microbiota, it remains obscure why the NAIP/NLRC4 pathway continues "ready-to-go." The administration of continues doses of LPS was found to be tolerogenic in mice (64), however any data are available about flagellin. We speculated that the increased IFN-a production in HIV-infected individuals (even if at lower levels in ARTtreated patients) could be a possible cause of specific NLRP3 inhibition due to the known effect of the anti-viral mediator as NLRP3 negative regulators (30). It is important to underline that our cohort of ART-treated HIV-infected individuals presented a mean value of plasma IFN-a of about $50 \mathrm{pg} / \mathrm{mL}, 5$-fold more than healthy individuals (about $10 \mathrm{pg} / \mathrm{mL}$ ) (data not shown). Moreover, when HD-DC were treated with IFN-a their NLRP3 response is diminished similarly to what observed in HIVDC (Figure 3F), supporting our hypothesis. Another possible explication concerns the higher constitutive recruitment of adaptor molecule ASC (Apoptosis speck like with a CARD) in inflammasome complex in HIV-infected patients compared to healthy controls as recently observed by Ahmad and colleagues (65) in PBMC. In this case, inflammasome receptors, which need ASC to mount the complex (i.e., NLRP3), could be disadvantaged in respect to sensors that directly recruit caspase-1, such as NLRC4. 
Beyond the main purpose of this article, and for the first time to our knowledge, we demonstrated that NLRP3 also contribute to flagellin response in human MDDC, as revealed by NLRP3+ specks formation in FLG-treated cells (Figure 4) and by specific (chemical and genetic) inhibition of this receptor (Figure 5). Our findings are in lines with previous reports about NLRC4 and NLRP3 co-localization into a unique complex in HEK293 cells (66) and in mice bone marrow-derived macrophages during Salmonella infection (67).

Therefore, flagellin induces the two pathways in HD-DC, whereas it preferentially activates NLRC4 pathway in HIVDC due to the defect in NLRP3 in these cells. Despite the immunofluorescence visualization of both NLRP3+ and NLRC4+ specks, our data are not sufficient to determine whether the two receptors are truly co-localized in the same inflammasome complex, and further investigations will be needed to finally prove it.

In conclusion, our data support the use of flagellin in the design of future vaccines effective also in immunocompromised individuals, such as HIV-infected patients. According to our findings, flagellin activates human MDDC from healthy and HIV-infected individuals through the NAIP/NLRC4 inflammasome, with the participation of NLRP3 at least in healthy donors cells. Flagellin was able to by-pass the NLRP3 defect in HIV-DC, contributing to inflammasome activation and consequently full MDDC maturation in HIV-infected patients.

\section{ETHICS STATEMENT}

All research involving human participants was approved by the Institutional Ethics Committees of Oswaldo Cruz Hospital, Hospital das Clinicas/Faculty of Medicine of the University of São Paulo (FMUSP) and of the Institute of Biomedical Science (ICB/USP). Written informed consent was obtained from all participants, and clinical investigations were conducted according to the principles expressed in the Declaration of Helsinki.

\section{AUTHOR CONTRIBUTIONS}

EdR, BdA, and AP: conceived and designed experiments. EdR: performed MDDC experiments. VL: collection of samples. DdL:

\section{REFERENCES}

1. Steinman RM. The dendritic cell system and its role in immunogenicity. Annu Rev Immunol. (1991) 9:271-96. doi: 10.1146/annurev.iy.09.040191. 001415

2. Banchereau J, Steinman RM. Dendritic cells and the control of immunity. Nature. (1998) 392:245-52. doi: 10.1038/32588

3. Wu L, Dakic A. Development of dendritic cell system. Cell Mol Immunol. (2004) 1:112-8.

4. Steinman RM. Dendritic cells: understanding immunogenicity. Eur J Immunol. (2007) (37Suppl. 1):S53-60. doi: 10.1002/eji.200737400

5. Maisonneuve C, Bertholet S, Philpott DJ, De Gregorio E. Unleashing the potential of NOD- and Toll-like agonists as vaccine adjuvants. Proc Natl Acad Sci USA. (2014) 111:12294. doi: 10.1073/pnas.1400478111 performed the immunofluorescence experiments. FF and JdS: ELISA. EdR, DdL, and AP: statistical analysis. EdR, DdL, VL, FF, and AP: discussion of results. EdR and AP: wrote the article. BdA: designed and discussed silencing experiments.

\section{FUNDING}

This project was supported by the Fundação de Amparo à Pesquisa do Estado de São Paulo (FAPESP) (research grant 2015/23395-6 and 2015/50660-7 to AP; 2014/23225-0 to BdA). ECR (2015/17373-0), VL (2017/10824-1) and FF (2018/043611) receive FAPESP post-graduation fellowships; JdS had received a CAPES master' degree fellowships; DdL receives a Ph.D. fellowship from the Fundação de Amparo à Pesquisa do Estado Amazonas (FAPEAM). AP receives a CNPq Researcher Fellowship. The funders had no role in this study design, data collection and analysis, decision to publish, or preparation of the manuscript.

\section{ACKNOWLEDGMENTS}

We are very grateful to the Oswaldo Cruz Hospital Blood Bank Service and the Serviço de Extensão ao Atendimento de Pacientes HIV/AIDS (SEAP) of the FMUSP (SP, Brazil) for the recruitment of healthy donors and HIV-infected patients, respectively. We acknowledge Prof. Niels Olsen Câmara for slide chambers and qPCR reagents; Dr. Telma Miyuki Oshiro for anti-human NLRP3 antibody, and IL-12p70 ELISA reagents; Prof. Karina Ramalho Bortoluci, Dr. Paula Ordonhez Rigato, and Prof. Silvia Boscardin for helpful suggestions and discussion. We acknowledge Prof. Eliana Faquim and the technician Alexsander Souza for the microscope facility of the Laboratory of Cellular Biology at the Butantan Institute (São Paulo, SP, Brazil) by the use of a DMi8 confocal laser scanning microscope; the Laboratory of Immune Cell Biology (Department of Immunology, ICB, USP) for technical support in silencing experiments.

\section{SUPPLEMENTARY MATERIAL}

The Supplementary Material for this article can be found online at: https://www.frontiersin.org/articles/10.3389/fimmu. 2019.01291/full\#supplementary-material 
cells in patients infected with HIV-1. Blood. (2003) 101:4505-11. doi: 10.1182/blood-2002-10-3189

11. Sabado RL, O’brien M, Subedi A, Qin L, Hu N, Taylor E, et al. Evidence of dysregulation of dendritic cells in primary HIV infection. Blood. (2010) 116:3839-52. doi: 10.1182/blood-2010-03-273763

12. Cardone M, Ikeda KN, Varano B, Gessani S, Conti L. HIV-1-induced impairment of dendritic cell cross talk with $\gamma \delta$ T lymphocytes. J Virol. (2015) 89:4798-808. doi: 10.1128/JVI.03681-14

13. Liu J, Ostrowski M. Development of targeted adjuvants for HIV-1 vaccines. AIDS Res Ther. (2017) 14:43. doi: 10.1186/s12981-017-0165-8

14. Pontillo A, Silva LT, Oshiro TM, Finazzo C, Crovella S, Duarte AJ. HIV-1 induces NALP3-inflammasome expression and interleukin-1beta secretion in dendritic cells from healthy individuals but not from HIV-positive patients. AIDS. (2012) 26:11-8. doi: 10.1097/QAD.0b013e32834d697f

15. Deeks SG, Tracy R, Douek DC. Systemic effects of inflammation on health during chronic HIV infection. Immunity. (2013) 39:633-45. doi: 10.1016/j.immuni.2013.10.001

16. Kool M, Pétrilli V, De Smedt T, Rolaz A, Hammad H, Van Nimwegen M, et al. Cutting edge: alum adjuvant stimulates inflammatory dendritic cells through activation of the NALP3 inflammasome. J Immunol. (2008) 181:3755-9. doi: 10.4049/jimmunol.181.6.3755

17. Hajam IA, Dar PA, Shahnawaz I, Jaume JC, Lee JH. Bacterial flagellina potent immunomodulatory agent. Exp Mol Med. (2017) 49:e373. doi: $10.1038 / \mathrm{emm} .2017 .172$

18. Hayashi F, Smith KD, Ozinsky A, Hawn TR, Yi EC, Goodlett DR, et al. The innate immune response to bacterial flagellin is mediated by Toll-like receptor 5. Nature. (2001) 410:1099-103. doi: 10.1038/35074106

19. Yoon SI, Kurnasov O, Natarajan V, Hong M, Gudkov AV, Osterman AL, et al. Structural basis of TLR5-flagellin recognition and signaling. Science. (2012) 335:859-64. doi: 10.1126/science.1215584

20. Diebolder CA, Halff EF, Koster AJ, Huizinga EG, Koning RI. Cryoelectron tomography of the NAIP5/NLRC4 inflammasome: implications for NLR activation. Structure. (2015) 23:2349-57. doi: 10.1016/j.str.2015.10.001

21. Hu Z, Zhou Q, Zhang C, Fan S, Cheng W, Zhao Y, et al. Structural and biochemical basis for induced self-propagation of NLRC4. Science. (2015) 350:399-404. doi: 10.1126/science.aac5489

22. Zhang L, Chen S, Ruan J, Wu J, Tong AB, Yin Q, et al. Cryo-EM structure of the activated NAIP2-NLRC4 inflammasome reveals nucleated polymerization. Science. (2015) 350:404-9. doi: 10.1126/science.aac5789

23. Treanor JJ, Taylor DN, Tussey L, Hay C, Nolan C, Fitzgerald T, et al. Safety and immunogenicity of a recombinant hemagglutinin influenza-flagellin fusion vaccine (VAX125) in healthy young adults. Vaccine. (2010) 28:8268-74. doi: $10.1016 /$ j.vaccine.2010.10.009

24. Turley CB, Rupp RE, Johnson C, Taylor DN, Wolfson J, Tussey L, et al. Safety and immunogenicity of a recombinant M2e-flagellin influenza vaccine (STF2.4xM2e) in healthy adults. Vaccine. (2011). 29:5145-52. doi: 10.1016/j.vaccine.2011.05.041

25. Sallusto F, Palermo B, Lenig D, Miettinen M, Matikainen S, Julkunen I, et al. Distinct patterns and kinetics of chemokine production regulate dendritic cell function. Eur J Immunol. (1999) 29:1617-25. doi: 10.1002/(SICI)15214141(199905)29:05<1617::AID-IMMU1617>3.0.CO;2-3

26. Gattorno M, Tassi S, Carta S, Delfino L, Ferlito F, Pelagatti MA, et al. Pattern of interleukin-1beta secretion in response to lipopolysaccharide and ATP before and after interleukin-1 blockade in patients with CIAS1 mutations. Arthritis Rheum. (2007) 56:3138-48. doi: 10.1002/art.22842

27. Coll RC, Robertson AA, Chae JJ, Higgins SC, Munoz-Planillo R, Inserra MC, et al. A small-molecule inhibitor of the NLRP3 inflammasome for the treatment of inflammatory diseases. Nat Med. (2015) 21:248-55. doi: 10.1038/nm.3806

28. Juliana C, Fernandes-Alnemri T, Wu J, Datta P, Solorzano L, Yu JW, et al. Anti-inflammatory compounds parthenolide and Bay 11-7082 are direct inhibitors of the inflammasome. J Biol Chem. (2010) 285:9792-802. doi: 10.1074/jbc.M109.082305

29. Guarda G, Braun M, Staehli F, Tardivel A, Mattmann C, Forster I, et al. Type I interferon inhibits interleukin-1 production and inflammasome activation. Immunity. (2011) 34:213-23. doi: 10.1016/j.immuni.2011.02.006

30. Simmons DP, Wearsch PA, Canaday DH, Meyerson HJ, Liu YC, Wang Y, et al. Type I IFN drives a distinctive dendritic cell maturation phenotype that allows continued class II MHC synthesis and antigen processing. J Immunol. (2012) 188:3116-26. doi: 10.4049/jimmunol.1101313

31. Da Silva LT, Da Silva WC, De Almeida A, Da Silva Reis D, Santillo BT, Rigato PO, et al. Characterization of monocyte-derived dendritic cells used in immunotherapy for HIV-1-infected individuals. Immunotherapy. (2018) 10:871-85. doi: 10.2217/imt-2017-0165

32. Shinde P, Fernandes S, Melinkeri S, Kale V, Limaye L. Compromised functionality of monocyte-derived dendritic cells in multiple myeloma patients may limit their use in cancer immunotherapy. Sci Rep. (2018) 8:5705. doi: 10.1038/s41598-018-23943-w

33. Schmittgen TD, Livak KJ. Analyzing real-time PCR data by the comparative C(T) method. Nat Protoc. (2008) 3:1101-8. doi: 10.1038/nprot.2008.73

34. Stutz A, Horvath GL, Monks BG, Latz E. ASC speck formation as a readout for inflammasome activation. Methods Mol Biol. (2013) 1040:91-101. doi: 10.1007/978-1-62703-523-1_8

35. Mccloy RA, Rogers S, Caldon CE, Lorca T, Castro A, Burgess A. Partial inhibition of Cdk1 in G 2 phase overrides the SAC and decouples mitotic events. Cell Cycle. (2014) 13:1400-12. doi: 10.4161/cc.28401

36. Baravalle G, Park H, Mcsweeney M, Ohmura-Hoshino M, Matsuki Y, Ishido $\mathrm{S}$, et al. Ubiquitination of CD86 is a key mechanism in regulating antigen presentation by dendritic cells. J Immunol. (2011). 187:2966-73. doi: 10.4049/jimmunol.1101643

37. Doitsh G, Galloway NLK, Geng X, Yang Z, Monroe KM, Zepeda O, et al. Cell death by pyroptosis drives CD4 T-cell depletion in HIV-1 infection. Nature. (2013) 505:509. doi: 10.1038/nature12940

38. Walsh JG, Reinke SN, Mamik MK, Mckenzie BA, Maingat F, Branton WG, et al. Rapid inflammasome activation in microglia contributes to brain disease in HIV/AIDS. Retrovirology. (2014) 11:35. doi: 10.1186/17424690-11-35

39. Bandera A, Masetti M, Fabbiani M, Biasin M, Muscatello A, Squillace N, et al. The NLRP3 inflammasome is upregulated in HIV-infected antiretroviral therapy-treated individuals with defective immune recovery. Front Immunol. (2018) 9:214. doi: 10.3389/fimmu.2018.00214

40. Feria MG, Taborda NA. HIV replication is associated to inflammasomes activation, IL-1beta, IL-18 and caspase-1 expression in GALT and peripheral Blood. PLoS ONE. (2018) 13:e0192845. doi: 10.1371/journal.pone.01 92845

41. Ito S, Hara Y, Kubota T. CARD8 is a negative regulator for NLRP3 inflammasome, but mutant NLRP3 in cryopyrin-associated periodic syndromes escapes the restriction. Arthritis Res Ther. (2014) 16:R52. doi: $10.1186 /$ ar 4483

42. Py BF, Kim MS, Vakifahmetoglu-Norberg H, Yuan J. Deubiquitination of NLRP3 by BRCC 3 critically regulates inflammasome activity. Mol Cell. (2013) 49:331-8. doi: 10.1016/j.molcel.2012.11.009

43. Segovia JA, Tsai S-Y, Chang T-H, Shil NK, Weintraub ST, Short JD, et al. Nedd8 regulates inflammasome-dependent caspase-1 activation. Mol Cell Biol. (2015) 35:582-97. doi: 10.1128/MCB.00775-14

44. Yang Z, Zhong L, Xian R, Yuan B. MicroRNA-223 regulates inflammation and brain injury via feedback to NLRP3 inflammasome after intracerebral hemorrhage. Mol Immunol. (2015) 65:267-76. doi: 10.1016/j.molimm.2014.12.018

45. Von Sydow M, Sonnerborg A, Gaines H, Strannegard O. Interferonalpha and tumor necrosis factor-alpha in serum of patients in various stages of HIV-1 infection. AIDS Res Hum Retrovirus. (1991) 7:375-80. doi: 10.1089/aid.1991.7.375

46. Khatissian E, Tovey MG, Cumont MC, Monceaux V, Lebon P, Montagnier $\mathrm{L}$, et al. The relationship between the interferon alpha response and viral burden in primary SIV infection. AIDS Res Hum Retrovirus. (1996) 12:1273-8. doi: 10.1089/aid.1996.12.1273

47. Stylianou E, Aukrust P, Bendtzen K, Muller F, Froland SS. Interferons and interferon (IFN)-inducible protein 10 during highly active antiretroviral therapy (HAART)-possible immunosuppressive role of IFN-alpha in HIV infection. Clin Exp Immunol. (2000) 119:479-85. doi: 10.1046/j.1365-2249.2000.01144.x

48. Kayagaki N, Wong MT, Stowe IB, Ramani SR, Gonzalez LC, AkashiTakamura S, et al. Noncanonical inflammasome activation by intracellular LPS independent of TLR4. Science. (2013) 341:1246-9. doi: $10.1126 /$ science. 1240248 
49. Kortmann J, Brubaker SW, Monack DM. Cutting edge: inflammasome activation in primary human macrophages is dependent on flagellin. $J$ Immunol. (2015) 195:815-9. doi: 10.4049/jimmunol.1403100

50. Blanchet FP, Moris A, Nikolic DS, Lehmann M, Cardinaud S, Stalder R, et al. Human immunodeficiency virus-1 inhibition of immunoamphisomes in dendritic cells impairs early innate and adaptive immune responses. Immunity. (2010) 32:654-69. doi: 10.1016/j.immuni.2010.04.011

51. Mcsorley SJ, Ehst BD, Yu Y, Gewirtz AT. Bacterial flagellin is an effective adjuvant for CD4+ $\mathrm{T}$ cells in vivo. J Immunol. (2002) 169:3914-9. doi: 10.4049/jimmunol.169.7.3914

52. Didierlaurent A, Ferrero I, Otten LA, Dubois B, Reinhardt M, Carlsen $\mathrm{H}$, et al. Flagellin promotes myeloid differentiation factor 88-dependent development of Th2-type response. J Immunol. (2004) 172:6922-30. doi: 10.4049/jimmunol.172.11.6922

53. Zheng JH, Nguyen VH, Jiang SN, Park SH, Tan W, Hong SH, et al. Two-step enhanced cancer immunotherapy with engineered Salmonella typhimurium secreting heterologous flagellin. Sci Transl Med. (2017) 9:9537. doi: 10.1126/scitranslmed.aak9537

54. Lu W, Arraes LC, Ferreira WT, Andrieu JM. Therapeutic dendriticcell vaccine for chronic HIV-1 infection. Nat Med. (2004) 10:1359-65. doi: $10.1038 / \mathrm{nm} 1147$

55. Ciacci-Woolwine F, Blomfield IC, Richardson SH, Mizel SB. Salmonella flagellin induces tumor necrosis factor alpha in a human promonocytic cell line. Infect Immun. (1998) 66:1127-34.

56. Buisson S, Benlahrech A, Gazzard B, Gotch F, Kelleher P, Patterson S. Monocyte-derived dendritic cells from HIV type 1-infected individuals show reduced ability to stimulate $\mathrm{T}$ cells and have altered production of interleukin (IL)-12 and IL-10. J Infect Dis. (2009) 199:1862-71. doi: 10.1086/599122

57. Franchi L, Amer A, Body-Malapel M, Kanneganti TD, Ozoren N, Jagirdar $\mathrm{R}$, et al. Cytosolic flagellin requires Ipaf for activation of caspase-1 and interleukin 1beta in salmonella-infected macrophages. Nat Immunol. (2006) 7:576-82. doi: 10.1038/ni1346

58. Miao EA, Alpuche-Aranda CM, Dors M, Clark AE, Bader MW, Miller SI, et al. Cytoplasmic flagellin activates caspase-1 and secretion of interleukin 1beta via Ipaf. Nat Immunol. (2006) 7:569-75. doi: 10.1038/ni1344

59. Kofoed EM, Vance RE. Innate immune recognition of bacterial ligands by NAIPs determines inflammasome specificity. Nature. (2011) 477:592-5. doi: 10.1038/nature10394

60. Canna SW, De Jesus AA, Gouni S, Brooks SR, Marrero B, Liu Y, et al. An activating NLRC4 inflammasome mutation causes autoinflammation with recurrent macrophage activation syndrome. Nat Genet. (2014) 46:1140-6. doi: 10.1038/ng.3089

61. Reyes Ruiz VM, Ramirez J, Naseer N, Palacio NM, Siddarthan IJ, Yan BM, et al. Broad detection of bacterial type III secretion system and flagellin proteins by the human NAIP/NLRC4 inflammasome. Proc Natl Acad Sci USA. (2017) 114:13242. doi: 10.1073/pnas.1710433114

62. Means TK, Hayashi F, Smith KD, Aderem A, Luster AD. The toll-like receptor 5 stimulus bacterial flagellin induces maturation and chemokine production in human dendritic cells. J Immunol. (2003) 170:5165. doi: 10.4049/jimmunol.170.10.5165

63. Maartens G, Celum C, Lewin SR. HIV infection: epidemiology, pathogenesis, treatment, and prevention. Lancet. (2014) 384:258-71. doi: 10.1016/S0140-6736(14)60164-1

64. Geisel J, Kahl F, Müller M, Wagner H, Kirschning CJ, Autenrieth IB, et al. IL-6 and maturation govern TLR2 and TLR4 induced TLR agonist tolerance and cross-tolerance in dendritic cells. J Immunol. (2007) 179:5811. doi: 10.4049/jimmunol.179.9.5811

65. Ahmad F, Mishra N, Ahrenstorf G, Franklin BS, Latz E, Schmidt RE, et al. Evidence of inflammasome activation and formation of monocytederived ASC specks in HIV-1 positive patients. AIDS. (2018) 32:299-307. doi: 10.1097/QAD.0000000000001693

66. Man SM, Hopkins LJ, Nugent E, Cox S, Glück IM, Tourlomousis P, et al. Inflammasome activation causes dual recruitment of NLRC4 and NLRP3 to the same macromolecular complex. Proc Natl Acad Sci USA. (2014) 111:74038. doi: 10.1073/pnas.1402911111

67. Qu Y, Misaghi S, Newton K, Maltzman A, Izrael-Tomasevic A, Arnott D, et al. NLRP3 recruitment by NLRC4 during Salmonella infection. J Exp Med. (2016) 213:877-85. doi: 10.1084/jem.20132234

Conflict of Interest Statement: The authors declare that the research was conducted in the absence of any commercial or financial relationships that could be construed as a potential conflict of interest.

Copyright (c) 2019 Reis, Leal, Soares, Fernandes, Souza de Lima, de Alencar and Pontillo. This is an open-access article distributed under the terms of the Creative Commons Attribution License (CC BY). The use, distribution or reproduction in other forums is permitted, provided the original author(s) and the copyright owner(s) are credited and that the original publication in this journal is cited, in accordance with accepted academic practice. No use, distribution or reproduction is permitted which does not comply with these terms. 